\title{
The Atlas of Reptiles of Iran. Omid Mozaffari, Kamran Kamali and Hadi Fahimi. 2016. Iran Department of the Environment, Tehran. 361 pp.
}

\author{
Aaron M. Bauer \\ Department of Biology, Villanova University, 800 Lancaster Avenue, Villanova, Pennsylvania 19085, USA \\ Corresponding author $\bowtie$ : aaron.bauer@villanova.edu
}

Herpetology in Iran is alive and well and experiencing an unprecedented period of productivity. Consequently, in recent years there have been several books dealing with the reptiles of Iran. Among these are works by Rastegar-Pouyani et al. (2007), Kamali (2017) and Rajabizadeh (2018). Although each of these makes a valuable contribution, these books were published in Farsi only, limiting their usefulness to those outside of Iran. Further, while all of these books are well-illustrated, only Rajabizadeh (2018) includes point locality maps, but it covers snakes only. The most recent English language book, Anderson (1999) is now 20 years old and, although still useful, is significantly out of date with respect to current taxonomy. Sindaco and Jeremčenko (2008) and Sindaco et al. (2013) include Iran in their treatment of Palearctic reptiles, but the level of geographic resolution is relatively coarse and only selected species are illustrated. Finally, several checklists and keys with updated taxonomy and extensive references (e.g., Rastegar-Pouyani et al., 2008; Šmíd et al., 2014; Safaei-Mahroo et al., 2015; Nasrabadi et al., 2017) are valuable, but they lack maps and photographs and serve neither as atlases nor field guides.

The Atlas of Reptiles of Iran is unique among treatments of the diverse Iranian reptile fauna in that the text is presented in both Farsi and English, maximizing its utility among both local and international readers. There are some issues with the English translation, but these do not affect the understanding of the text. The book has color throughout. My review copy was digital and the maps and figures were reasonably crisp when viewed at actual page size.

The book begins with a detailed map of the many parks, wildlife refuges and other protected areas in Iran. The introductory text includes a short, simple, non-technical overview of reptiles, as well as short sections on skin and skin shedding, (including labeled diagrams of lizard and snake head scalation and chelonian scutes), evolutionary history, feeding and digestion, metabolism, circulation, respiration, urinary morphology, hibernation and aestivation, reproduction, defense, and sensory organs. A section on the importance of reptiles highlights, cultural, economic and scientific values of these animals and is followed by a section on threats. Separate keys (both Farsi and English) are provided for the species of lizards, snakes and chelonians.

The bulk of the book is devoted to species accounts. These are prefaced with a guide to a series of icons that accompany each account. These conveniently summarize a good deal of information in a small space and obviate the need for bilingual text. These include the CITES 
status of species and their IUCN threat categories, as well as the protection level in Iran (based on Department of the Environment rankings), and an objective assessment of abundance, based on likely encounter rates. Other icons provide information on diet and habitat (14 categories each), and species toxicity (venomous = proteroglyphous and solenoglyphous snakes versus semi-venomous $=$ opisthoglyphous snakes) .

Each species account occupies one page and includes a point locality map plotted on a topographic map of Iran showing provincial boundaries. Except for a single species, Cyrtopodion brevipes (Blanford), one or usually two, color photos illustrate each account. Typically, a small image is associated with the icons, and a larger image occupies the bottom third or fourth of each page. The scientific and common names, an abbreviated synonymy, and sections on "exterior characteristics", "global distribution", "reproduction", and "behavior" take up the remainder of the page, while a color-coded vertical bar at the edge of the page groups the species by family.

In all, 225 species are included, divided as follows: Agamidae (18 species), Anguidae (2 species), Eublepharidae (3 species), Gekkonidae including Phyllodactylidae and Sphaerodactylidae (51 species), Lacertidae (40 species), Scincidae (17 species), Uromastycidae (3), Varanidae (2), Boidae (6), Colubridae, including Lamprophiidae (43), Elapidae (11 species, nine of which are sea snakes), Leptotyphlopidae (2), Typhlopidae (2), Viperidae (13), Cheloniidae (4), Dermochelyidae (1), Emydidae (1), Geoemydidae (1), Trionychidae (1), Testudinidae (2), Crocodylidae (1 species), and Trogonophidae (1).

The Atlas is now several years old and some new species have been described since it appeared, however, new taxa described as long ago as 2013 are also missing, as are taxonomic changes and new records that post-date 2012. For example, in the Agamidae, three of the species listed in the Atlas as Laudakia Gray are now assigned to Paralaudakia (Baig et al., 2012) and Trapelus sanguinolentus (Pallas), considered present in Iran by Šmíd et al. (2014), is not included in the book. Laudakia fusca (Blanford), which is listed as a full species is usually considered a subspecies of L. nupta (De Filippi), and Trapelus lessonae (De Filippi), which has a species account has been shown to be a junior synonym of T. ruderatus (Olivier) (Ananjeva et al., 2013). In addition, there are three Phrynocephalus Kaup described since 2013 that are not included.

The Gekkonidae as treated herein actually includes three gekkotan families that have been recognized since 2008, the Phyllodactylidae (represented in Iran by genus Asaccus Dixon and Anderson), the Sphaerodactylidae (represented by Teratoscincus Strauch), and the Gekkonidae sensu stricto (all other genera) (Gamble et al., 2008). Within the Gekkonidae, Bauer et al. (2013) reallocated naked-toed geckos to genus on the basis of a partial phylogeny of the group. The taxonomy used here predates this work and thus the species now allocated to genus Microgecko Nikolsky are here all included in Tropiocolotes Peters, Tenuidactylus caspius (Eichwald) and T. turcmenicus (Szczerbak) are listed in the Atlas as Cyrtopodion Fitzinger, and Cyrtopodion kirmanense (Nikolsky) is given as Mediodactylus kirmanense, this last example highlights a minor nomenclatural problem.

Because the generic name Cyrtopodion is neuter in gender and Mediodactylus Szczerbak and Golubev and Tenuidactylus Szczerbak and Golubev are masculine, they require different endings for specific epithets. Thus, Cyrtopodion sistanensis should be $C$. sistanense Nazarov and Rajabizadeh (neuter) and Mediodactylus hetercercum should be M. heterocercus (Blanford) (masculine). Trigonodactylus (formerly Stenodactylus) arabicus Haas was documented in Iran in 2014 (Fathinia et al., 2014) and seven new species, including the type of the new genus Parsigecko (Safaei-Mahroo et al., 2016), are not covered, nor is Rhinogecko femoralis (Smith), which was recognized from Iran by Šmíd et al. (2014). 
Among the Scincidae, one new species is lacking and the three species of Iranian Trachylepis Fitzinger are now assigned to Heremites Gray (Karin et al., 2016) and in the Varanidae, a third species, $V$. nesterovi, endemic to the western Zagros Mountains, is now recognized (Böhme et al., 2015). Four recently described lacertids of the genus Darevskia Arribas by Ahmadzadeh et al. (2013) are lacking, as well as Eremias kopetdaghica Szczerbak (raised to full species by Šmíd et al., 2014), E. suphani Başoğlu and Hellmich (recorded for Iran by Rastegar-Pouyani et al., 2013), and Mesalina bernoullii (Schenkel) and M. microlepis (Angel) (demonstrated by Šmíd et al., 2017 to be distinct from M. brevirostris Blanford). This family also has some problems with the matching of generic and specific gender, e.g. Eremias montanus (should be montana) Rastegar-Pouyani and Rastegar-Pouyani, and Timon kurdistanica (should be kurdistanicus) (Suchow).

Even if the boids (now commonly considered Erycidae) occurring in Iran have not changed, the identity of some of the species in the northeast of the country has been reevaluated somewhat from what is presented in this book (Eskandarzadeh et al., 2013). Colubridae as used in the Atlas also includes snakes that have for some time been placed in the Lamprophiidae, a family more closely related to elapids than true colubrids (Kelly et al., 2011). These include Psammophis Fitzinger and Malpolon Fitzinger. In the latter genus, $M$. moilensis (Reuss) is listed under Scutophis Brandstätter, one of several generic names applied to this species. Among true colubrids, two species have been described since 2013 and so are lacking. Eirenis persicus (Anderson) is listed under the genus Pseudocyclophis Boettger, now usually considered a synonym or subgenus of Eirenis Jan, and the taxon usually called Boiga trigonata melanocephalus (Annandale) is accorded specific status.

Among elapids the authors are lacking one recently described terrestrial species and an additional sea snake, Hydrophis (or Microcephalophis) cantoris Günther, initially reported from the Persian Gulf by Safaei and Esmaili (2009) and recently confirmed from Iranian waters (Rezaie-Atagholipour et al., 2016). The sea snakes taxonomy of the Atlas does not follow that of Sanders et al. (2012), who synonymized most generic names with Hydrophis Latreille (also affecting the suffixes of numerous specific epithets), which is now widely accepted. Among the vipers, Gloydius caucasicus (Nikolsky) is typically regarded as a full species (treated as G. halys (Pallas) in the Atlas) and the very recently described species Macrovipera razii Oraie, Rastegar-Pouyani, Khosrovani, Moradi, Akbari, Sehhatisabet, Shafiei, Stümpel and Joger is, of course, lacking.

In scolecophidian snakes the movement of Iranian Typhlops Oppel to Xerotyphlops and of Ramphotyphlops braminus (Daudin) to Indotyphlops (Hedges et al., 2014) have not been implemented and one recently described species, as well as X. wilsoni (Wall) (known only from its Iranian type), are likewise lacking. Chelonians, crocodiles, amphisbaenians, anguids, uromastycids, eublepharids and leptotyphlopids are up to date.

The references section includes almost 800 citations and provides a useful overview of publications dealing with the reptiles of Iran and adjacent areas, although hardly any of these are actually cited anywhere in the text, exclusive of some associated with names in the brief synonymies. But these are not uniformly or systematically included, as, for example, there are no publications listed by Pallas, who was the original describer of nine of the species for which accounts are provided. Most of the entries appear to be correct, with only scattered minor inconsistencies, like a lack of italics on some Latin names.

As for the taxa in the book, the references also stop at 2012 (for which only three references are listed), so users will need to access some of the more recent checklists and books cited at the opening of this review in order to bring the bibliography up-to-date. 
Overall, The Atlas of Reptiles of Iran provides a non-technical overview of the reptiles of the country that can be used by a wide audience. The relatively simple text is a contrast to the point locality maps and the extensive bibliography, both of which will be of more interest to specialists. The obvious drawback of the book is that so many taxonomic changes and new descriptions post-date the book's apparent 2012 cutoff. By their very nature, books such as this are necessarily out-of-date as soon as they are published.

However, in this case, there has been so much activity in Iranian herpetology that the knowledge gap after even a few years is quite obvious. Nonetheless, paired with recent national checklists and keys (e.g., Šmíd et al., 2014; Safaei-Mahroo et al., 2015; Nasrabadi et al., 2017), this book will provide a generally reliable, well-illustrated atlas to the diverse and dynamic reptile fauna of Iran.

\section{References}

Ahmadzadeh, F., Flecks, M., Carretero, M. A., Mozaffari, O., Böhme, W., Harris, D. J., Freitas, S. and Rödder, D. (2013). Cryptic speciation patterns in Iranian rock lizards uncovered by integrative taxonomy. PLOS ONE, 8 (12): e80563. http://dx.doi.org/ 10.1371/journal.pone.0080563

Ananjeva, N. B., David, P., Barabanov, A. V. and Dubois, A. (2013). On the type specimens of Trapelus ruderatus (Olivier, 1804) and some nomenclatural problems on Trapelus Cuvier, 1816 (Agamidae, Sauria). Russian Journal of Herpetology, 20 (3): 197-202. http://dx.doi.org/10.30906/1026-2296-2019-20-\%25s-197-202

Anderson, S. C. (1999). The Lizards of Iran. Society for the Study of Amphibians and Reptiles, Oxford, Ohio, $442 \mathrm{pp}$.

Baig, K. J., Wagner, P., Ananjeva, N. and Böhme, W. (2012). A morphology-based taxonomic revision of Laudakia Gray, 1845 (Squamata: Agamidae). Vertebrate Zoology, 62 (2): 213-260.

Bauer, A. M., Masroor, R., Titus-Mcquillan, J., Heinicke, M. P., Daza, J. D. and Jackman, T. R. (2013). A preliminary phylogeny of the Palearctic naked-toed geckos (Reptilia: Squamata: Gekkonidae) with taxonomic implications. Zootaxa, 3599 (4): 301-324. http://dx.doi.org/10.11646/zootaxa.3599.4.1

Böhme, W., Ehrlich, K., Milto, K., Orlov, N. and Scholz, S. (2015). A new species of desert monitor lizard (Varanidae: Varanus: Psammosaurus) from the western Zagros region (Iraq, Iran). Russian Journal of Herpetology, 22 (1): 41-52. http://dx.doi.org/10. 30906/1026-2296-2019-22-\%25s-41-52

Eskandarzadeh, N., Darvish, J., Rastegar-Pouyani, E. and Ghassemzadeh, F. (2013). Reevaluation of the taxonomic status of sand boas of the genus Eryx (Daudin, 1803) (Serpentes: Boidae) in northeastern Iran. Turkish Journal of Zoology, 37 (3): 348-356. http://dx.doi.org/ 10.3906/zoo-1205-1

Fathinia, B., Gholamifard, A. and Rastegar-Pouyani, N. (2014). First record of Stenodactylus arabicus (Haas, 1957) from Iran. Herpetozoa, 26 (3/4): 169-173.

Gamble, T., Bauer, A. M., Greenbaum, E. and Jackman, T. R. (2008). Out of the blue: a novel, trans-Atlantic clade of geckos (Gekkota, Squamata). Zoologica Scripta, 37 (4): 355-366. https://doi.org/10.1111/j.1463-6409.2008.00330.x

Hedges, S. B., Marion, A. B., Lipp, K. M., Marin, J. and Vidal, N. (2014). A taxonomic framework for typhlopid snakes from the Caribbean and other regions (Reptilia, Squamata). Caribbean Herpetology, 49: 1-61. https://doi.org/10.31611/ch.49 
Kamali, K. (2017). The Field Guide of Reptiles and Amphibians of Iran [in Farsi]. Iranshensai Publishing, Tehran. 368 pp.

Karin, B. R., Metallinou, M., Weinell, J. L., Jackman, T. R. and Bauer, A. M. (2016). Resolving the higher-order phylogenetic relationships of the circumtropical Mabuya group (Squamata: Scincidae): An out-of-Asia diversification. Molecular Phylogenetics and Evolution, 102: 220-232. https://doi.org/10.1016/j.ympev.2016.05.033

Kelly, C. M. R., Branch, W. R., Broadley, D. G., Barker, N. P. and Villet, M. H. (2011). Molecular systematics of the African snake family Lamprophiidae Fitzinger, 1843 (Serpentes: Elapoidea), with particular focus on the genera Lamprophis Fitzinger 1843 and Mehelya Csiki 1903. Molecular Phylogenetics and Evolution, 58 (3): 415-426. https://doi.org/10.1016/j.ympev.2010.11.010

Nasrabadi, R., Rastegar-Pouyani, N., Rastegar-Pouyani, E. and Gharzi, A. (2017). A revised key to the lizards of Iran (Reptilia: Squamata: Lacertilia). Zootaxa, 4227 (3): 431-443. https://doi.org/10.11646/zootaxa.4227.3.9

Rajabizadeh, M. (2018). Snakes of Iran [in Farsi]. Iranshensai Publishing, Tehran. 496 pp.

Rastegar-Pouyani, N., Johari, S. M. and Rastegar-Pouyani, E. (2007). Field Guide to the Reptiles of Iran (Volume 1: Lizards) [in Farsi]. Razi University Press, Kermanshah. 139 $+12+[1]+\mathrm{ix}+$ VII, 119 pp. pls.

Rastegar-Pouyani, E., Avci, A., Kumlutaş, Y., Ilgaz, Ç. and Hosseinian Yousefkhani, S. S. (2013). New country record and range extension of Eremias suphani Başoğlu \& Hellmich, 1968 from Iran. Amphibian and Reptile Conservation, 6 (2): 35-39.

Rastegar-Pouyani, N., Kami, H. G., Rajabzadeh, M., Shafiei, S. and Anderson, S. C. (2008). Annotated checklist of amphibians and reptiles of Iran. Iranian Journal of Animal Biosystematics, 4 (1): 43-66.

Rezaie-Atagholipour, M., Ghezellou, P., Hesni, M. A., Dakhteh, S. M. H., Ahmadian, H. and Vidal, N. (2016). Sea snakes (Elapidae, Hydrophiinae) in their westernmost extent: an updated and illustrated checklist and key to the species in the Persian Gulf and Gulf of Oman. ZooKeys, 622: 129-164. https://doi.org/10.3897/zookeys.622.9939

Safaei, M. and Esmaili, H. R. (2009). Identification and distribution of sea snakes (Serpentes: Hydrophiidae) in the coastal waters of the Persian Gulf and Gulf of Oman [in Farsi]. Quarterly of Marine Research, 1 (1): 37-49 [not seen by author].

Safaei-Mahroo, B., Ghaffari, H. and Anderson, S. C. (2016). A new genus and species of gekkonid lizard (Squamata: Gekkota: Gekkonidae) from Hormozgan Province, with a revised key to gekkonid genera of Iran. Zootaxa, 4109 (4): 428-444. http://doi.org/10.11646/zootaxa.4109.4.2

Safaei-Mahroo, B., Ghaffari, H., Fahimi, H., Broomand, S., Yazdanian, M., Najafi Majd, E., Hosseinian Yousefkhani, S. S., Rezazadeh, E., Hosseinzadeh, M. S., Nasrabadi, R., Rajabizadeh, M., Mashayekhi, M., Motesharei, A., Naderi, A. and Kazemi, S. M. (2015). The herpetofauna of Iran: checklist of taxonomy, distribution and conservation status. Asian Herpetological Research, 6 (4): 257-290. https://doi.org/10.16373/j.cnki.ahr. 140062

Sanders, K. L., Lee, M. S. Y., Mumpuni, M., Bertozzi, T. and Rasmussen, A. R. (2012). Multilocus phylogeny and recent rapid radiation of the viviparous sea snakes (Elapidae: Hydrophiinae). Molecular Phylogenetics and Evolution, 66 (3): 575-591. https://doi.org/10.1016/j.ympev.2012.09.021

Sindaco, R. and Jeremčenko, V. K. (2008). The Reptiles of the Western Palearctic. 1. Annotated Checklist and Distributional Atlas of the Turtles, Crocodiles, Amphisbaenians 
and Lizards of Europe, North Africa, Middle East and Central Asia. Edizioni Belvedere, Latina, Italy, $579 \mathrm{pp}$.

Sindaco, R., Venchi, A. and Grieco, C. (2013). The Reptiles of the Western Palearctic. Volume 2: Annotated Checklist and Distributional Atlas of the Snakes of Europe, North Africa, Middle East and Central Asia, with an Update to Volume 1. Edizioni Belvedere, Latina, Italy, $543 \mathrm{pp}$.

Šmíd, J., Moravec, J., Gvoždík, V., Štundl, J., Frynta, D., Lymberakis, P., Kapli, P., Wilms, T., Schmitz, A., Shobrak, M., Hosseinian Yousefkhani, S., Rastegar-Pouyani, E., Castilla, A. M., Els, J. and Mayer, W. (2017). Cutting the Gordian Knot: Phylogenetic and ecological diversification of the Mesalina brevirostris species complex (Squamata, Lacertidae). Zoologica Scripta, 46 (6): 649-664. https://doi.org/10.1111/zsc.12254

Šmíd, J., Moravec, J., Kodym, P., Kratochvíl, L., Hosseinian Yousefkhani, S. S., RastegarPouyani, E. and Frynta, D. (2014). Annotated checklist and distribution of the lizards of Iran. Zootaxa, 3855 (1): 1-97. http://dx.doi.org/10.11646/zootaxa.3855.1.1 